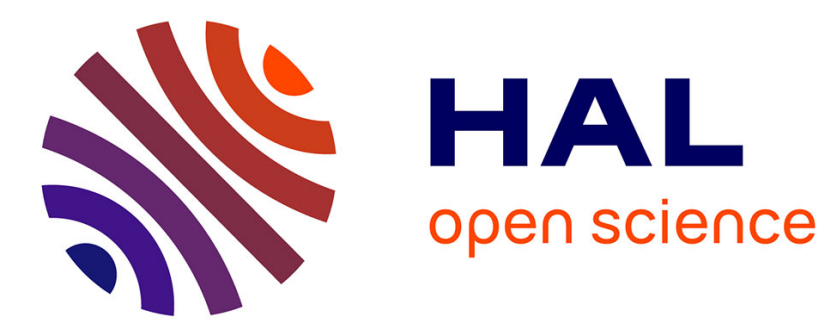

\title{
Assessing the variety and pricing of selected foods in socioeconomically disparate districts of Berlin, Germany
}

Nanette Stroebele, Pia Dietze, Peter Tinnemann, Stefan N. Willich

\section{To cite this version:}

Nanette Stroebele, Pia Dietze, Peter Tinnemann, Stefan N. Willich. Assessing the variety and pricing of selected foods in socioeconomically disparate districts of Berlin, Germany. Journal of Public Health, 2010, 19 (1), pp.23-28. 10.1007/s10389-010-0357-3 . hal-00564773

\section{HAL Id: hal-00564773 \\ https://hal.science/hal-00564773}

Submitted on 10 Feb 2011

HAL is a multi-disciplinary open access archive for the deposit and dissemination of scientific research documents, whether they are published or not. The documents may come from teaching and research institutions in France or abroad, or from public or private research centers.
L'archive ouverte pluridisciplinaire HAL, est destinée au dépôt et à la diffusion de documents scientifiques de niveau recherche, publiés ou non, émanant des établissements d'enseignement et de recherche français ou étrangers, des laboratoires publics ou privés. 
Editorial Manager(tm) for Journal of Public Health

Manuscript Draft

Manuscript Number: JOPH-D-10-00023R1

Title: Assessing variety and pricing of selected foods in socioeconomic disparate districts of Berlin, Germany

Article Type: Original Article

Corresponding Author: Dr. Nanette Stroebele, PhD

Corresponding Author's Institution: Charité University Medical Centre, Berlin, Germany

First Author: Nanette Stroebele, PhD

Order of Authors: Nanette Stroebele, PhD; Pia Dietze; Peter Tinnemann, Dr. med.; Stefan N Willich, Prof

Abstract: Aim: The neighbourhood environment appears to influence people's food consumption. Access, variety and pricing of foods play a role in the socioeconomic difference of fruit and vegetable consumption. This study compared differences in number of grocery stores, variety of fresh fruits and vegetables and food prices in districts with different Social Index (SI) in Berlin, Germany.

Methods: The district with the lowest SIs was compared to the district with the highest SI. The number of grocery stores offering fresh produce, the variety of fresh fruits and vegetables, and prices of selected healthy and less healthy food items were assessed and compared.

Results: The low SI district had more grocery stores per residents than the high SI district. Variety and prices of fruits and vegetables did not differ between the two districts but milk and whole wheat bread were less expensive in the high SI district. For all grocery stores, selected foods with higher energy density had lower energy costs than low energy density foods.

Conclusion: Health inequalities in Germany might be less influenced by access to healthy foods than in other countries but nutrient rich foods such as fruits and vegetables have higher energy costs than high energy dense foods.

Response to Reviewers: Response to reviewer's comments:

The authors provide no explanation why cigarettes are included in the study, which deals with pricing of food. Cigarettes don't belong to any group of food, so it has to be explained why they are analysed in this context as well.

- The authors have decided to exclude the item "cigarettes" from the analysis and the manuscript. The authors agree with the reviewer that the topic of cigarette pricing and its relationship to socioeconomic differences does not belong in this manuscript.

p. 2, 1st paragraph: ". behaviour. ", should use similar terms as in the rest of the text.

- The British orthography was used and all words were changed accordingly. 
p. 5, 1st paragraph: The two areas Kreuzberg and Steglitz-Lankwitz are compared, but the population density is given for the three areas: Kreuzberg, Steglitz and Lankwitz. This is confusing and should be clarified.

- Official data only provides population density separately for Steglitz and Lankwitz but the authors hopefully clarified this confusion by calculating the mean for both areas.

p. 5, 1st paragraph and p. 9, 3rd paragraph: information about the size of the two areas is inconsistent: p. 5 ". roughly the same size. ", p. 9 ". size. differed."

- The information regarding the size of the areas chosen was clarified.

p. 5, 3rd paragraph: It should be explained in this paragraph why the variety of food items was determined only in non-organic food stores (compare p.6, 1st paragraph).

- A sentence explaining the reasons for choosing only non-organic food stores was added (p. 5, 3rd paragraph)

p. 6, 1st paragraph: Which established criteria for the popularity for the chosen food products in the German population were used?

- A reference was added.

p. 7, 1st paragraph: ". framers' markets. ", should use similar terms as of the rest of the text.

- For all markets, the expression "farmers' markets" was chosen.

p. 8, 2nd paragraph: The relationship between energy density and energy costs should be explained shortly in the part "results", only referring to the figure would not be sufficient.

- The results presented in figure 1 were explained in more details (p. 8, 2nd paragraph).

p. 9, last paragraph and p. 11, 1st paragraph are identical.

- The last paragraph on page 9 was taken out. 
Assessing variety and pricing of selected foods in socioeconomic disparate districts of Berlin, Germany.

Stroebele N, Dietze P, Tinnemann P, Willich SN.

Institute for Social Medicine, Epidemiology and Health Economy

Charité University Medical Centre, Berlin, Germany

Corresponding Author

Nanette Stroebele

Institute for Social Medicine, Epidemiology and Health Economy

Charité University Medical Centre

Luisenstr. 57

D- 10117 Berlin, Germany

Fax: +49 30450529902

Phone : +49 30450529125

Email: Nanette.Stroebele@charite.de

RUNNING HEAD: Environment, Food Variety and Pricing 
1

Keywords: environment, fruit and vegetables, pricing, accessibility, variety 


\section{Introduction}

Unhealthy dietary behaviour, in particular the consumption of fruits and vegetables has been shown to be particularly low among socioeconomically disadvantaged populations (Giskes et al. 2002; Hulshof et al. 2003). A systematic review revealed that household income appears to be consistently positively related to fruit and vegetable intake (Kamphuis et al. 2006) and lower socioeconomic groups seem to be less likely to follow existing dietary guidelines (Turrell et al. 2002).

Another factor that has been gaining attention recently is the possible influence of neighbourhood food environment. Recent studies from the U.S. suggest that residents of socioeconomically disadvantaged neighbourhoods have less access to affordable healthy food choices compared to high socioeconomic neighbourhoods (Jetter et al. 2006; Hendrickson et al. 2006; Chung et al. 1999; Moore et al. 2006; Powell et al. 2007; Zenk et al. 2009). Healthier food choices in deprived areas differ in their availability, variety and in price compared to healthier choices in less deprived areas. In deprived areas fewer variety of fresh fruits and vegetables is offered and fresh produce tend to be more expensive (Hosler et al. 2008; Zenk et al. 2005). However, other studies show few or no differences in food prices, availability or access between deprived and affluent areas (Cassady et al. 2007; Smith et al. 2009; Winkler et al. 2006a; Winkler et al. 2006b). Two recent systematic reviews examining the empirical evidence found only little evidence for the influence of environmental factors on fruit and vegetable consumption (Giskes et al. 2007;Kamphuis et al. 2007).

\footnotetext{
Another aspect of the food environment has been gaining attention in the public health sector; high energy dense foods, high fat foods and general convenience, processed foods including fast
} 
food tend to be cheaper than healthy foods such as fresh fruits or vegetables (Drewnowski et al. 2004; Darmon et al. 2004). Research on dietary behaviour and social inequalities suggest that low income households rather purchase energy dense foods that are nutrient poorer but are at an affordable cost compared to more expensive nutrient rich foods such as fresh fruits and vegetables (Drewnowski et al. 2005; Drewnowski 2009). Data from the U.S. shows an inverse relationship between the energy density of foods and the energy costs measured in USD/1000kcal (Drewnowski et al. 2005). It is possible that lower food costs might be associated with higher energy dense diets which might lead to an increase in total energy intake. As a consequence, the higher prevalence of overweight and obesity in socio-economically disadvantaged groups could be explained by this imbalance of economics of food choice. Research in the area of food environment and social inequality in Germany is lacking. Although socioeconomic inequalities is less pronounced in Germany compared to other countries (van Doorslaer et al. 2004; Hernandez-Quevedo et al. 2006), prior research has shown that people of low economic standing in Germany have above average rates of malnutrition, eating disorders and obesity (Mackenbach et al. 2008; Robert Koch-Institut 2006). The capital city of Germany, Berlin, consists of a number of districts where inhabitants live under conditions differing widely by their socioeconomic situation such as income, unemployment rate, and ethnic background as well as in their health and disease status (Senatsverwaltung für Gesundheit 2009).

In this pilot study, we sought to determine if differences in the food neighbourhood environment are apparent in Berlin, Germany. We analyzed the two districts with the largest social economic disparity and studied their availability of stores, produce prices and fruit and vegetable variety. 


\section{Methods}

This study investigated access to food within two districts in Berlin comparing the districts with the lowest and highest socioeconomic population. The study examined (1) the number of grocery stores offering fresh produce; (2) the variety of fresh fruits and vegetables available to the consumers; and (3) the prices of a series of food items defined as healthy and unhealthy. Healthy food items included a series of popular fresh fruits and vegetables, milk and whole-wheat bread. As unhealthy, energy dense food items, such as frozen pizza, chocolate, and potato chips were chosen.

\section{Setting}

Two areas in Berlin similar in size but with a widely different socioeconomic population were selected. The socioeconomic difference between the two areas was determined by a complex measuring tool called the Social Index (SI) created by the city of Berlin (Senatsverwaltung für Gesundheit 2009). The SI was developed to determine social differences between Berlin's neighbourhoods and to create a common ground for analysis and planning of social communities. Among other things, the index is based on unemployment rates, average per capita income, number of people on social welfare, and life span expectancy. We chose to study the area of Kreuzberg which lies within the community district of Kreuzberg-Friedrichshain and represents the neighborhood with one of lowest SI in Berlin based on the SI of 2008. The other area chosen was Steglitz and Lankwitz which is an area within the community district of Steglitz-Zehlendorf. Steglitz-Zehlendorf represents the neighborhood with the highest SI in Berlin in 2008. The net household income in Kreuzberg-Friedrichshain in 2006 was $€ 1,175$ per months whereas the net household income in Steglitz-Zehlendorf was $€ 1,850$. The areas are roughly of the same size 
(10.4 km2 for Kreuzberg and $13.8 \mathrm{~km}^{2}$ for Steglitz and Lankwitz) but population density is higher in Kreuzberg (14.239 residents/km²) compared to Steglitz and Lankwitz (8.085 residents $/ \mathrm{km}^{2}$; Steglitz is 10.391 residents $/ \mathrm{km}^{2}$ and Lankwitz is 5.778 residents $/ \mathrm{km}^{2}$ ).

\author{
Availability \\ Within the districts the number of food stores including organic grocery stores and farmers' \\ markets were counted. Food stores were identified through systematic investigation of each and \\ every street within the established district borders. Farmers' markets were located through \\ internet research. Food stores were defined as stores that offer at least one type of fresh vegetable \\ and one type of fresh fruit (except lemons or limes). Food stores had to be open at least 5 \\ days/week for 8 hours/day. Farmers' markets were included if they were open for at least 6 \\ hours/week. Availability was defined as the number of food stores and farmers' markets per \\ 10.000 residents.
}

Variety of fresh fruits and vegetables within food stores

Variety of food items was determined through the visual count of different kinds of fresh fruit and vegetables available at each store by a trained surveyor to all non-organic food stores during the months of May through July 2009. Given that organic food stores are still relatively rare as well as usually limited in their fruit and vegetable variety, only non-organic food stores and foods were assessed. The following fresh fruit and vegetable items were summarized into larger categories and counted as one: berries (strawberries, cranberries, raspberries, blackberries), lemon (lemon and limes), melons (watermelons, cantaloupes, honeydew), and cabbage (red cabbage, green cabbage, chinese cabbage). To control for seasonal variation and to increase 
comparability, we collected data concurrently in both districts and completed data collection within 12 weeks.

\section{Pricing}

For the purpose of price comparison between stores and districts, the most economical price for a sample of 12 products was recorded. The 12 products were chosen because of their popularity among the German population (DFHV, 2009). Food prices of the following 12 food products were measured: apples, bananas, tomatoes, carrots, potatoes, whole wheat bread, fresh milk, frozen pizza, chocolate, potato chips, and beer. Since the most economical price for each food was often found in bulk quantities we calculated prices for predetermined amounts. Prices for fresh fruit and vegetable items were noted per one kilogram (1000 grams). Prices for whole wheat bread, chocolate and chips were recorded per 100 grams. Fresh milk prices were recorded as price per carton ( 1 liter), beer prices as the cost per 0.5 liter, and frozen pizza as price for one pizza (300 grams). Organic food stores were not entered to record prices or produce variety because high quality standards often cause costs to increase which makes sold items unaffordable to many people and high prices would result in distorted price averages.

\section{Statistical Analysis}

Analysis of variance was used to examine differences by district (low SI vs. high SI) in the mean number of fruits and vegetables and the mean lowest prices of the selected food items available in all stores. Using the average caloric content of selected food items $(100 \mathrm{~g}$ pizza $=\mathrm{ca} .216 \mathrm{kcal}$, $100 \mathrm{~g}$ potato chips $=\mathrm{ca} .547 \mathrm{kcal}, 100 \mathrm{~g}$ chocolate $=\mathrm{ca} .536 \mathrm{kcal}, 100 \mathrm{~g}$ apples $=\mathrm{ca} .49 \mathrm{kcal}, 100 \mathrm{~g}$ 
bananas $=$ ca. $95 \mathrm{kcal}, 100 \mathrm{~g}$ carrots $=$ ca. $25 \mathrm{kcal})$, the relationship between energy costs (Euro $€ / 1,000 \mathrm{kcal})$ and energy density $(\mathrm{kcal} / \mathrm{g})$ of each food item was calculated.

\section{Results}

The low SI district (Kreuzberg) had greater access to supermarkets compared to the district with high SI (Steglitz + Lankwitz). Per 10,000 residents, in the low SI district 5.88 food stores (including farmer markets and organic food stores; $\mathrm{N}=87$ ) were available compared to only 4.42 food stores in the high SI district $(\mathrm{N}=46)$. More organic food stores and farmers' markets were available in the low SI area compared to the high SI area.

Number of types of fruits and vegetables in the low SI district did not differ significantly from the number of types of fruits and vegetables in the high SI district (table 1).

- insert table 1 -

In the low SI district, prices of the selected food items were assessed in 72 grocery stores including 13 supermarkets, 23 discounters, and 36 farmers' markets. In the high SI district only 45 grocery stores including 18 supermarkets, 18 discounters, and nine farmers' markets were found. Including all types of food stores (super markets, discounters and farmers' markets) fruits and vegetables did not differ in pricing between the two districts. No differences were found for apples, bananas, tomatoes, carrots and beer. Potatoes $(\mathrm{F}=9,122, \mathrm{p}=0.003)$, whole-wheat bread $(\mathrm{F}=9,527, \mathrm{p}=0.003)$, fresh milk $(\mathrm{F}=56,179, \mathrm{p}=0.000)$, chocolate $(\mathrm{F}=40,489, \mathrm{p}=0.000)$, potato chips $(\mathrm{F}=32,655, \mathrm{p}=0.000)$, and frozen pizza $(\mathrm{F}=5,819, \mathrm{p}=0.018)$ were significantly 
cheaper in the high SI district compared to the low SI district (table 1). However, when the local farmers' markets which were more common in the low SI district were taken out of the analysis, the only four remaining items that were less expensive in the high SI district were whole-wheat bread $(0,16$ vs. 0,$14 ; \mathrm{F}=20,208, \mathrm{p}=0.000)$, fresh milk $(0,50$ vs. 0,$48 ; \mathrm{F}=6,634, \mathrm{p}=0.012)$, and potato chips $(0,29$ vs. 0,$28 ; \mathrm{F}=6,081, \mathrm{p}=0.016)$. Without the farmers' markets, bananas were cheaper in the low SI district compared to the high SI district $(1,18$ vs. 1,$13 ; \mathrm{F}=10,589, \mathrm{p}=$ $0.002)$.

To compare pricing of selected low and high energy dense foods, the mean prices of all grocery stores for the following food items were chosen: chocolate, potato chips, pizza, apples, bananas and carrots. Figure 1 shows the relationship between energy density (kcal/g) and energy costs (Euro€/1,000kcal) of a selection of low and high energy dense foods. It shows that energy costs

for apples $(3,26 € / 1,000 \mathrm{kcal})$, bananas $(4,10 € / 1,000 \mathrm{kcal})$, and carrots $(4,88 € / 1,000 \mathrm{kcal})$ are higher than for pizza $(2,16 € / 1,000 \mathrm{kcal})$, potato chips $(0,84 € / 1,000 \mathrm{kcal})$, and chocolate $(0,66 € / 1,000 \mathrm{kcal})$ whereas energy density is higher for pizza $(2,16 \mathrm{kcal} / \mathrm{g})$, potato chips $(5,47 \mathrm{kcal} / \mathrm{g})$, and chocolate $(5,36 \mathrm{kcal} / \mathrm{g})$ compared to apples $(0,49 \mathrm{kcal} / \mathrm{g})$, bananas $(0,95 \mathrm{kcal} / \mathrm{g})$ and carrots $(0,25 \mathrm{kcal} / \mathrm{g})$.

- insert figure 1 -

\section{Discussion}

The variety and prices of the examined food items were similar in the high and low socioeconomic districts. More grocery stores per 10.000 residents were found in the low SI area compared to the high SI area. The variety of fruits and vegetables did not differ between the districts and no differences could be found in terms of fruit and vegetable prices. These findings 
are in line with several other studies (Smith et al. 2009; Zenk et al. 2009; Cassady et al. 2007) . However, other food items such as fresh milk and whole wheat bread tended to be cheaper in the high SI district which in part supports the idea that healthy food choices tend to be more expensive in more disadvantaged neighbourhoods.

Looking at high-fat/energy-dense foods such as pizza, potato chips and chocolate significantly higher prices were observed in the low SI neighborhood. A possible explanation for the higher prices could be that grocery stores simply sell some of products at a higher price in neighbourhoods with a higher demand for these types of foods and products. Since this effect is mainly observed for unhealthy food items and not for fruits and vegetables it raises the question of the possibility of existing health inequity based on socio-economic standing.

In general, food pricing in Germany appears to be similar to food pricing in other nations with energy dense foods to be the lowest cost dietary options. For people with low SI, the financial aspect of foods most likely plays a crucial role in their purchase behaviour.

\section{Limitations of this study}

Several limitations of this study need to be mentioned. This was a pragmatic case-study approach with the focus on two geographically comparable areas in one particular city. Mainly the population density between the two districts differed. This approach does not allow the comparison of associations between neighbourhood deprivation and food accessibility for the full range of urban and rural settings across the world or even across Germany only. The findings of this study can only be generalized to the study region and spatial inequality might exist in rural and small town settings in Germany. In addition, no information on 
residents' shopping behaviours was obtained and food quality was also not addressed. Other food outlets such as convenience stores without fresh fruits and vegetables, restaurants, snack bars that might play a role in determining food item pricing were also not examined.

\section{Possible Implications and future research}

To our knowledge, this is the first study in Germany looking at neighbourhood food environments. The findings showed that the food environment in a socioeconomically disadvantaged area was as conducive to buying healthier food choices as in a more advantaged area. One possible explanation could be that within the German population social inequality is less pronounced than in other countries such as the U.S. and therefore the difference of social status in the chosen urban districts was too small to be a factor in the food environment. However, for the districts observed, energy dense foods were cheaper and therefore potentially more in demand in low SI districts than nutrient rich foods. Nevertheless, while prices for healthy foods appear to be similar in the districts, the purchase of such foods is determined by financial resources available to buyers. In particular, food inequity could be questioned since people with lower purchasing power have to pay similar prices for healthy foods compared to those with higher purchasing power.

Our findings could suggest that inequalities in food intake may have little to do with the food environment in Germany but rather the economics of food choice. Social inequality in Germany has been linked to obesity and other chronic disease and as Drewnowski and colleagues (Drewnowski et al. 2005; Drewnowski 2004) have recently pointed out, more likely factors for the lower nutritional quality of diets of low-income households could be the low cost of energydense foods. Thus, as long as energy dense foods are highly palatable and cheaper we believe it 
will be difficult to change low-income household's food choices and health inequity through pricing remains.

Further research needs to be conducted not only in other geographical areas in Germany and Europe in general but also other mechanisms such as cooking skills and habits in households as well as food costs and its relationship with energy density need to be examined. Currently not enough is known if and how household and food shopping environments affect population intake of fruits and vegetables and its relationship to socioeconomic inequalities in food intake.

\section{Conflict of interest statement}

The authors declare that they have no conflict of interest. 


\section{References}

Cassady D, Jetter KM, Culp J (2007) Is price a barrier to eating more fruits and vegetables for low-income families? J Am Diet Assoc 107:1909-1915.

Chung C, Myers SL (1999) Do the poor pay more for food? An analysis of grocery store availability and food price disparities. Journal of Consumer Affairs 33: 276-296

Darmon N, Briend A, Drewnowski A (2004) Energy-dense diets are associated with lower diet costs: a community study of French adults. Public Health Nutr 7:21-27

Deutscher Fruchthandelsverband e.V., DFHV (2009). Obst und Gemüse in Deutschland. Bonn Drewnowski A (2009) Obesity, diets, and social inequalities. Nutr Rev 67 Suppl 1:S36-S39 Drewnowski A (2004) Obesity and the food environment: dietary energy density and diet costs. Am J Prev Med 27:154-162

Drewnowski A, Darmon N (2005) Food choices and diet costs: an economic analysis. J Nutr 135:900-904 
Drewnowski A, Specter SE (2004) Poverty and obesity: the role of energy density and energy costs. Am J Clin Nutr 79:6-16

Giskes K, Kamphuis CB, van Lenthe FJ, Kremers S, Droomers M, Brug J (2007) A systematic review of associations between environmental factors, energy and fat intakes among adults: is there evidence for environments that encourage obesogenic dietary intakes? Public Health Nutr 10:1005-1017

Giskes K, Turrell G, Patterson C, Newman B (2002) Socio-economic differences in fruit and vegetable consumption among Australian adolescents and adults. Public Health Nutr 5:663-669

Hendrickson D, Smith C, Eikenberry N (2006) Fruit and vegetable access in four low-income food deserts communities in Minnesota. Agriculture and Human Values 23:371-383

Hernandez-Quevedo C, Jones AM, Lopez-Nicolas A, Rice N (2006) Socioeconomic inequalities in health: a comparative longitudinal analysis using the European Community Household Panel. Soc Sci Med 63:1246-1261

Hosler AS, Rajulu DT, Fredrick BL, Ronsani AE. (2008). Assessing retail fruit and vegetable availability in urban and rural underserved communities. Preventing Chronic Disease. Public Health Research, Practice, and Policy 5: A123 
Hulshof KF, Brussaard JH, Kruizinga AG, Telman J, Lowik MR (2003) Socio-economic status, dietary intake and 10 y trends: the Dutch National Food Consumption Survey. Eur J Clin Nutr $57: 128-137$

Jetter KM, Cassady DL (2006) The availability and cost of healthier food alternatives. Am J Prev Med 30:38-44

Kamphuis CB, Giskes K, de Bruijn GJ, Wendel-Vos W, Brug J, van Lenthe FJ (2006)

Environmental determinants of fruit and vegetable consumption among adults: a systematic review. Br J Nutr 96:620-635

Kamphuis CB, van Lenthe FJ, Giskes K, Brug J, Mackenbach JP (2007) Perceived environmental determinants of physical activity and fruit and vegetable consumption among high and low socioeconomic groups in the Netherlands. Health Place 13:493-503

Mackenbach JP, Stirbu I, Roskam AJ, Schaap MM, Menvielle G, Leinsalu M, Kunst AE (2008) Socioeconomic inequalities in health in 22 European countries. N Engl J Med 358:2468-2481

Moore LV, ez Roux AV (2006) Associations of neighborhood characteristics with the location and type of food stores. Am J Public Health 96:325-331

Powell LM, Slater S, Mirtcheva D, Bao Y, Chaloupka FJ (2007) Food store availability and neighborhood characteristics in the United States. Prev Med 44:189-195 
Robert Koch-Institut. Gesundheit in Deutschland. Gesundheitsberichterstattung des Bundes. 2006. Berlin, Robert Koch-Institut

Senatsverwaltung für Gesundheit UuV. Spezialbericht 2009-1: Sozialstrukturatlas Berlin 2008 Ein Instrument der quantitativen, interregionalen und intertemporalen Sozialraumanalyse und planung. 2009. Berlin, Senatsverwaltung für Gesundheit, Umwelt und Verbraucherschutz

\author{
Smith DM, Cummins S, Taylor M, Dawson J, Marshall D, Sparks L, Anderson AS (2010) \\ Neighbourhood food environment and area deprivation: spatial accessibility to grocery stores \\ selling fresh fruit and vegetables in urban and rural settings. Int J Epidemiol 39:277-284
}

Turrell G, Hewitt B, Patterson C, Oldenburg B, Gould T (2002) Socioeconomic differences in food purchasing behaviour and suggested implications for diet-related health promotion. J Hum Nutr Diet 15:355-364

van Doorslaer E, Koolman X (2004) Explaining the differences in income-related health inequalities across European countries. Health Econ 13:609-628

\author{
Winkler E, Turrell G, Patterson C (2006a) Does living in a disadvantaged area mean fewer \\ opportunities to purchase fresh fruit and vegetables in the area? Findings from the Brisbane food \\ study. Health Place 12:306-319
}


Winkler E, Turrell G, Patterson C (2006b) Does living in a disadvantaged area entail limited opportunities to purchase fresh fruit and vegetables in terms of price, availability, and variety? Findings from the Brisbane Food Study. Health Place 12:741-748

Zenk SN, Lachance LL, Schulz AJ, Mentz G, Kannan S and Ridella W (2009) Neighborhood retail food environment and fruit and vegetable intake in a multiethnic urban population. Am J Health Promot 23:255-264

Zenk SN, Schulz AJ, Israel BA, James SA, Bao S and Wilson ML (2005) Neighborhood racial composition, neighborhood poverty, and the spatial accessibility of supermarkets in metropolitan Detroit. Am J Public Health 95:660-667 
Table 1. Fruit and vegetable variety and mean pricing in Euro $(€)$ and Standard Error of the Mean (SEM) of foods by neighbourhood socioeconomic standing.

\begin{tabular}{|l|c|c|}
\hline & Low SES & High SES \\
& $(\mathrm{N}=72)$ & $16.09(3.23)$ \\
\hline Number of fruits (SD) & $14.21(5.94)$ & $20.64(4.14)$ \\
\hline Number of vegetables (SD) & $18.75(6.13)$ & $1,49(, 08)$ \\
\hline Apples $(1000 \mathrm{~g})$ in $€(\mathrm{SEM})$ & $1,44(, 06)$ & $1,42(, 07)$ \\
\hline Bananas $(1000 \mathrm{~g})$ in $€(\mathrm{SEM})$ & $1,39(, 05)$ & $1,59(, 11)$ \\
\hline Tomatoes $(1000 \mathrm{~g})$ in $€(\mathrm{SEM})$ & $1,93(, 09)$ & $1,12(, 06)$ \\
\hline Carrots $(1000 \mathrm{~g})$ in $€(\mathrm{SEM})$ & $1,30(, 04)$ & $0,84(, 04) \dagger$ \\
\hline Potatoes $(1000 \mathrm{~g})$ in $€(\mathrm{SEM})$ & $0,85(, 05)$ & $0,14(, 00) \dagger$ \\
\hline Whole-wheat bread $(100 \mathrm{~g})$ in $€(\mathrm{SEM})$ & $0,19(, 03)$ & $0,48(, 00) \dagger$ \\
\hline Fresh milk (11) in $€(\mathrm{SEM})$ & $0,63(, 04)$ & $0,71(, 01)^{*}$ \\
\hline Frozen pizza $(300 \mathrm{~g})$ in $€(\mathrm{SEM})$ & $0,83(, 06)$ & $0,36(, 00) \dagger$ \\
\hline Chocolate $(100 \mathrm{~g})$ in $€(\mathrm{SEM})$ & $0,51(, 04)$ & $3,28(, 01) \dagger$ \\
\hline Potato chips $(100 \mathrm{~g})$ in $€(\mathrm{SEM})$ & $0,46(, 04)$ & $(, 03) \dagger$ \\
\hline Beer $(0.5 \mathrm{l})$ in $€(\mathrm{SEM})$ & $3,39(, 03)$ & \\
\hline Cigarettes $(17 \mathrm{per}$ packet) in $€(\mathrm{SEM})$ & & \\
\hline
\end{tabular}

$* \mathrm{p}<0.05$

$\dagger \mathrm{p}<0.01$ 


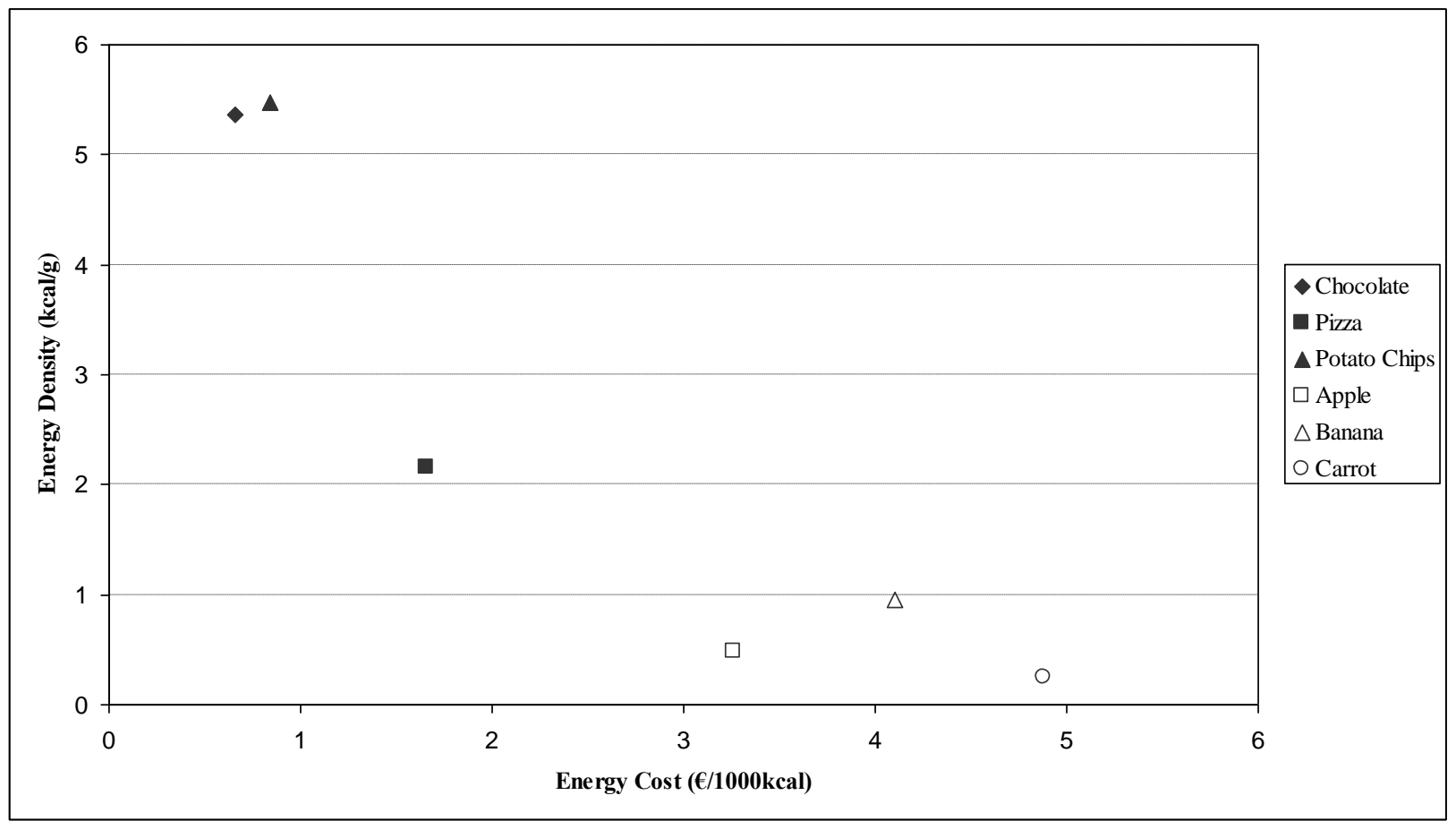

Figure 1. Relationship between energy density ( $\mathrm{kcal} / \mathrm{g})$ and energy costs (Euro€/1,000kcal) of selected food items 